Plasticity Under Pressure Using a Windowed Pressure-Shear Impact Experiment

J. N. Florando, T. Jiao, S. E. Grunschel, R. J. Clifton, D. H. Lassila, L. Ferranti, R. C. Becker, R. W. Minich, G. Bazan

March 18, 2010

Society for Experimental Mechanics Indianapolis, IN, United States June 7, 2010 through June 10, 2010 
This document was prepared as an account of work sponsored by an agency of the United States government. Neither the United States government nor Lawrence Livermore National Security, LLC, nor any of their employees makes any warranty, expressed or implied, or assumes any legal liability or responsibility for the accuracy, completeness, or usefulness of any information, apparatus, product, or process disclosed, or represents that its use would not infringe privately owned rights. Reference herein to any specific commercial product, process, or service by trade name, trademark, manufacturer, or otherwise does not necessarily constitute or imply its endorsement, recommendation, or favoring by the United States government or Lawrence Livermore National Security, LLC. The views and opinions of authors expressed herein do not necessarily state or reflect those of the United States government or Lawrence Livermore National Security, LLC, and shall not be used for advertising or product endorsement purposes. 


\title{
Plasticity Under Pressure Using a Windowed Pressure-Shear Impact Experiment
}

\author{
J.N. Florando*1, T. Jiao ${ }^{2}$, S. E. Grunschel ${ }^{2,3}$, R.J. Clifton ${ }^{2}$, D. H. Lassila ${ }^{1}$, L. Ferranti ${ }^{1}$, \\ R. C. Becker ${ }^{1,3}$, R.W. Minich ${ }^{1}$, and G. Bazan ${ }^{1}$ \\ ${ }^{1}$ Lawrence Livermore National Laboratory, ${ }^{2}$ Division of Engineering, Brown University, \\ ${ }^{3}$ U.S. Army Research Laboratory \\ * Corresponding Author: 7000 East Ave., M/S L-340, Livermore, CA 94550. florando1@lln.gov
}

Many experimental techniques have been developed to determine the compressive strength or flow stress of a material under high strain rate or shock loading conditions [1-3]. In addition, pressure-shear techniques have been developed that allow for the measurement of the shearing response of materials under pressure [4-6]. The technique described is similar to the traditional pressure-shear plate-impact experiments except that window interferometry is used to measure both the normal and transverse particle velocities at a sample-window interface. The velocities are measured using the normal displacement interferometer (NDI) for the normal velocity, and the transverse displacement interferometer (TDI) for the transverse velocity [7].

A schematic of the experiment is shown in Figure 1. For our experiment, the diameters of the impactor, sample and window are $31.75 \mathrm{~mm}$. A $3 \mathrm{~mm}$ thick Ta-10W flyer is used for all the experiments, and the window material is a $10 \mathrm{~mm}$ thick c-cut sapphire. Two types of samples, both polycrystalline $\mathrm{Cu}$ and $\mathrm{V}$ have been tested and have a nominal thickness of $1.5 \mathrm{~mm}$. For the TDI measurement a 1200 lines $/ \mathrm{mm}$ grating is etched in the sapphire and a thin $(\sim 120 \mathrm{~nm})$ metallic film is deposited over the grating. The sample attached to the film side of the window by application of glue at several locations on the outer circumference of the sample.

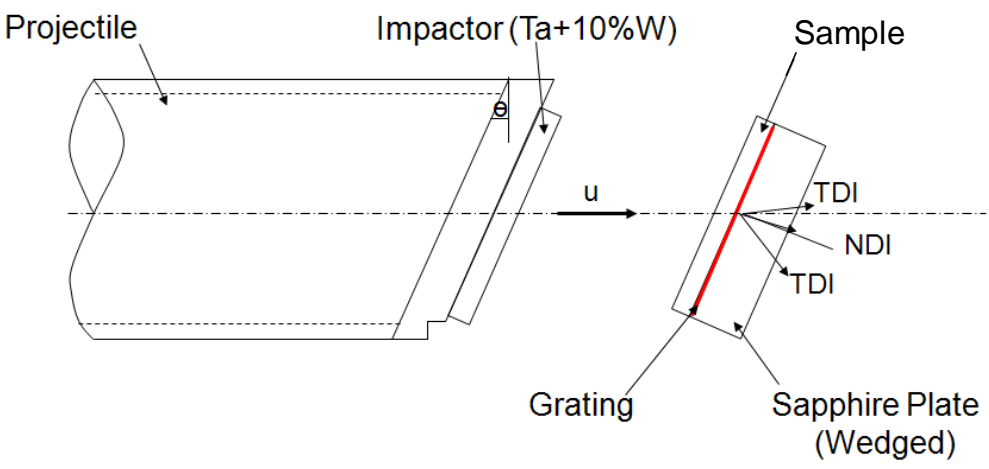

Figure 1. Schematic of the experiment 
The experimental result for a $\mathrm{Cu}$ experiment is shown in figure 2. Figure 2a shows an example of the interferomentric data from the NDI and TDI measurement taken at the sample/window interface. For the TDI measurement (pink) each fringe is equivalent to a the transverse displacement of $416 \mathrm{~nm}$. The velocity is calculated by taking the derivative as a function of time, and the experimental velocity data are shown in Figure $2 \mathrm{~b}$. The flow stress of the material is extracted by using a LLNL hydrodynamics code, ALE3D, and an appropriate strength model. For the Cu experiments, the Mechanical Threshold Model (MTS) [8] is used and can be matched to the transverse velocity profile with parameters that calculate a flow stress of $180 \mathrm{MPa}$. Similar experiments have also been performed on polycrystalline $\mathrm{V}$ and calculate a flow stress of approximately $600 \mathrm{MPa}$ [9].

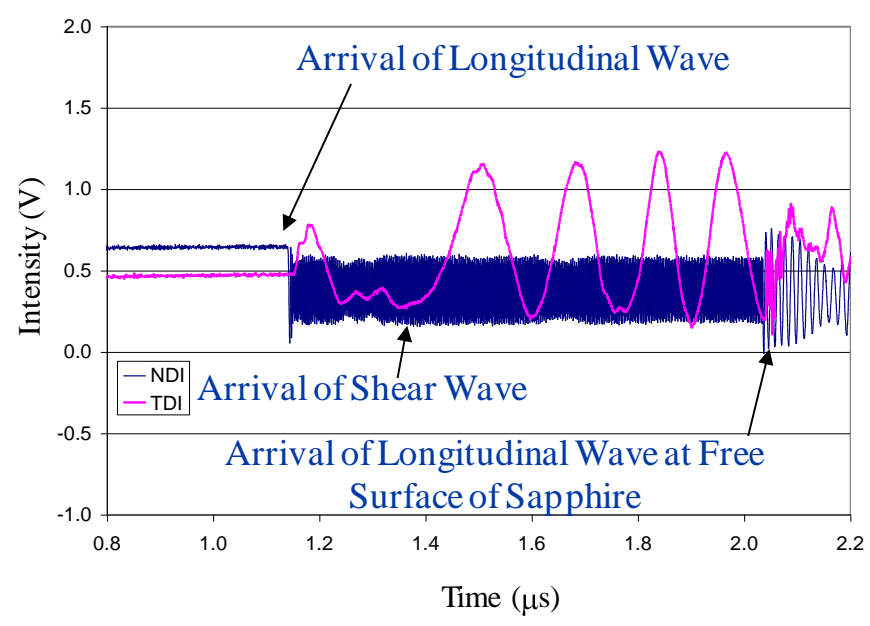

a)

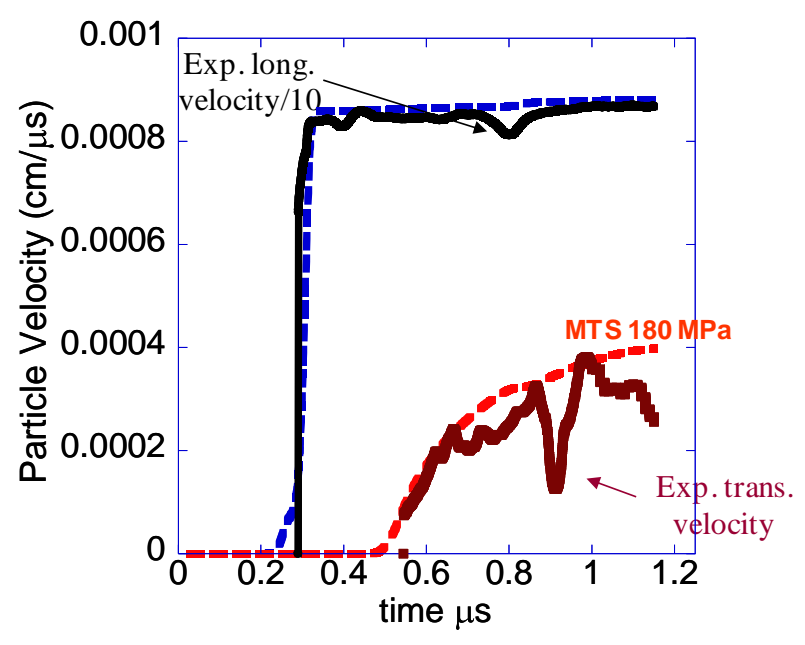

b)

Figure 2- a) NDI and TDI record measured at the Cu/sapphire interface. b) Experimental longitudinal and transverse particle velocities compared with hydrodynamics simulations. The MTS model predicts a flow stress for the Cu of $180 \mathrm{MPa}$.

\section{Acknowledgments}

Funding was provided by the LLNL Laboratory Directed Research and Development and the WCI "Dynamics of Metals" programs. This work was performed under the auspices of the U.S. Department of Energy by Lawrence Livermore National Laboratory under Contract DE-AC52-07NA27344.

\section{References}

1. Asay, J.R. and Lipkin, J., "A Self Consistent Technique for Estimating the Dynamic Yield Strength of a Shock Loaded Material", J. of Applied Physics 49, 4242, 1978.

2. Barker, LM, Lundergan, CD and Herrmann, W, "Dynamic Response of Aluminum", J. of Applied Physics 35, 1203, 1964.

3. Fowles, GR, "Shock Wave Compression of Hardened and Annealed 2024 Aluminum", J. of Applied Physics 32, 1475, 1961.

4. Clifton, R.J., Klopp, R.W. and Student, G., "Pressure-Shear Plate Impact Testing", ASM Handbook 230, 1985.

5. Yuan, G., Feng, R. and Gupta, Y.M., "Compression and Shear Wave Measurements to Characterize the Shocked State in Silicon Carbide", J. of Applied Physics 89, 5372, 2001.

6. Espinosa, H.D., "Dynamic Compression-Shear Loading with in-Material Interferometric Measurements", Rev. of Scientific Instruments 67, 3931-3939, 1996.

7. Kim, K.S., Clifton, R.J. and Kumar, P., "A Combined Normal and Transverse Displacement Interferometer with an Application to Impact of Y Cut Quartz", J. of Applied Physics 48, 4132, 1977.

8. Follansbee P.S., and Kocks, U.F., "A Constitutive Description of the Deformation of Copper Based on the Use of the Mechanical Threshold Stress as an Internal State Variable", Acta Metall. 36, 81, 1988.

9. Florando, J.N., et al., "High Rate Plasticity Under Pressure Using a Windowed Pressure-Shear Impact Experiment", Proc. Shock Comp of Cond. Matter. 1195, 723, 2010. 